\title{
El constitucionalismo en el Derecho Administrativo. Crisis de la jurisdicción rogada
}

\section{Constitutionalism in Administrative Law. Crisis of prayed jurisdiction}

\begin{abstract}
Arif Asor Andrade Arroyo ${ }^{1}$ Jaider Manuel Núñez Amaril²
JUSTICIA

ARTíCULO DE

INVESTIGACIÓN

Recibido: $05-07-17$

Aceptado: 10-08-17

Publicado: 18-01-18

DOI:

https://doi.org/10.17081//ust.23.33.288

1 Mst en Argumentación Jurídica de la Universidad de Alicante. Correo electrónico: arif.andrade@mail.uniatlantico.edu.co

2 MsC en Derecho de la UNAL. Correo electrónico: conoceteatimismo17@hotmail.com

RESUMEN

El Derecho Administrativo colombiano está impregnado con un fuerte barniz de jurisdicción rogada, si bien de suma importancia en el desarrollo de muchos temas, presenta grandes contradicciones en el Derecho Administrativo desde el derecho constitucional colombiano. Veremos las fuentes históricas interpretativas en las que se ha desarrollado la dialéctica que se presenta entre el Estado constitucional de derecho y la justicia rogada en el Derecho Administrativo colombiano, y cómo el debate entre paradigmas hermenéuticos como el Positivismo y Jusnaturalismo han sido la fuente fundamental de las apreciaciones jurídicas en el marco de la jurisdicción rogada. Así mismo, la influencia de las nuevas concepciones del Derecho Administrativo desde una óptica constitucional de la mano de principios como el iura novit curia ofrecen acercamientos hacia una justicia material efectiva en el Derecho Laboral Administrativo.

Palabras clave: Argumentación, interpretación, paradigma, proporcionalidad y ponderación.

\section{ABSTRACT}

Colombian Administrative Law is permeated with strong varnish prayed jurisdiction, and although of great importance in the development of many topics, this presents great contradictions between the Administrative Law from the Colombian constitutional law. We shall see interpretive historical sources which developed the dialect that occurs between the constitutional rule of law and justice entreaty in Colombian Administrative Law, and as the debate between hermeneutic paradigms, such as Positivism and Natural law, were the primary source of legal appreciations under the prayed jurisdiction. Likewise, the influence of new conceptions of Administrative Law from a constitutional perspective, including main such as hand iura curia novit, offer approaches towards effective material justice in Administrative Labor Law.
\end{abstract}

Keywords: Argumentation, interpretation, paradigm, proportionality and weighting. 


\section{INTRODUCCIÓN}

La jurisdicción contenciosa se caracteriza por ser un derecho eminentemente rogado, lo cual no permite que el juez pueda referirse a situaciones o normas que no han sido invocadas por las partes en la demanda, o porque no ha sido pedido o manifestado en el concepto de la violación ${ }^{3}$; a diferencia de la jurisdicción ordinaria en la que el juez puede fallar más allá de lo pedido (principio lura novit curia) que obliga al juez a saber el derecho y escoger la norma que se considera aplicable al caso concreto, en lo cual, se repite, debe respetarse la congruencia, en armonía con principios en algunos casos indeterminados, dependiendo la situación particular.

En el derecho contencioso administrativo, la justicia rogada ${ }^{4}$ rige en toda la actuación y se cumple como dogma de fe, sin que siquiera se pregunte por qué rige, o con una mera explicación irracional o como se explica lo inexplicable en derecho, o simplemente porque sí $i^{5}$. Por ser el Derecho Administrativo un derecho estatal originario de la herencia magnánima del Estado francés, en la que poco o nada podía argumentarse en su proceder, tal y como describió Eduardo García de Enterría (2007): "la idea de exigir judicialmente a la administración por modo directo ese respeto a la ley, y el dogma de no separar la administración de la justicia" (p. 18). Lo cual conlleva hacer reconocer judicialmente las incurias del Estado procesalmente, impidiendo la aplicación práctica de los principios constitucionales.

Profundizando en esta línea de pensamiento, García de Enterría (2007) alcanza el punto culminante de su tesis al defender un cambio de paradigma para la justicia administrativa. Su libro Transformaciones de la justicia administrativa: de excepción singular a la plenitud jurisdiccional. ¿Un cambio de paradigma? concluye así: hoy el juez contencioso-administrativo tiene la obligación de tutelar en su plenitud ese espacio de libertad que el ciudadano contemporáneo ha conquistado definitivamente y solo desde el cual puede

3 Sobre el tema, Consejo de Estado colombiano, Sección primera, sentencia del 30 de julio de 1993, Rad. 2262, M.P. Yesid Rojas Serrano; y sentencias de 8 de junio de 2000, Rad. 11121, M.P. María Elena Giraldo Gómez y de 17 de agosto de 2000, Rad. 12640, M.P. Alier Hernández Enríquez.

4 Este principio tiene sus orígenes en Francia donde se requería resolver los conflictos con el Estado, en principio, ante la jurisdicción contenciosa únicamente podía acudirse para impugnar en acción ciudadana el acto contrario a la legislación, lo cual estaba dado para resolver las actuaciones de la administración, donde el accionante no tenía facultades para probar en contra de lo que se hubiera discutido, probado 0 analizado en la instancia administrativa. No había posibilidad de pedir y practicar pruebas en el proceso, ni introducir argumentaciones diferentes a las que se hubieran tenido en la actuación administrativa, de allí la denominación de proceso de revisión, lo cual denota un afán por proteger las actuaciones de la administración teniendo en cuenta el principio de legalidad, y el interés general de la administración pública (García de Enterría, 2007, p. 138).

5 Más que principio es solo una regla de conducta que tiene sus orígenes en situaciones no judiciales del Consejo de Estado francés, al cual se acudía para consultarle su opinión sobre las inquietudes del rey y luego las consultas del gobierno, de tal manera que solo se podía contestar lo preguntado. 
ser capaz de construir y proteger una vida personal plenaria en su integridad (p. 138).

Solo ahora, por vez primera en toda su larga historia, el juez contencioso-administrativo al haber ganado esa plenitud de jurisdicción ha pasado a ser definitivamente capaz, en efecto, de otorgar a los ciudadanos una justicia plenaria y efectiva. Esta es la formidable actualidad de la técnica contenciosa-administrativa de protección del ciudadano tras sus últimas y bien recientes regulaciones, a pesar de ello, es necesario imbuir la garantía constitucional del constituyente en los procesos administrativos, lo cual implica desrrogativizar el derecho administrativo e indeterminar aspectos administrativos.

Así mismo, la subjetivación definitiva de la justicia administrativa, que ha roto el mito histórico de su supuesta objetividad, tras el cual se enmascaraba una superioridad formal de la administración sobre el ciudadano, considerado aún como súbdito que debía ceder ante la supuesta superioridad de "los intereses generales" (p. 138). Gestionados por la administración es ya una ganancia definitiva y por ello definitivamente irrenunciable de nuestro tiempo.

La Jurisdicción Contencioso Administrativa presenta fallos cada vez más limitados e injustos, por las restricciones que el principio de jurisdicción rogada impone, al estar las pretensiones de la parte actora circunscritas a las decisiones judiciales, cuando el juez podría adoptar medidas que restablecieran completamente el derecho, tomando como base principios constitucionales de garantía no solo para el ciudadano, sino también para la protección de los mismos intereses del Estado ${ }^{6}$, si bien al juez no le está dado cercenar la ley, a la ley tampoco le es dado cercenar las garantías constitucionales del ciudadano, claro está, que es necesario distinguir los hechos reales sobre la simple ideología reinante, en el momento de efervescencia política, en este sentido Kelsen (2011) después de rectificar su postura frente al Estado de derecho aun en los regímenes fascistas, reconsidera el filósofo positivista "debe entenderse un cierto tipo de Estado, aquel que responda a las exigencias de la democracia y de la certeza del derecho"(p. 138).

De tal manera que, al engranar la situación jurídica en disputa con los principios constitucionales, la rogatividad que opera al ejercerse el control de legalidad podría hacerse menos rígida, de modo que aun cuando una norma no sea invocada como infringida, la ostensibilidad en su violación o la prueba

6 Basta con remembrar la frase "el Estado no tiene dolientes" para dejar por sentado que las defensas en los procesos judiciales presentan una flaca defensa sin que el juez pueda tomar cartas en el asunto por las limitantes que presenta el principio de la jurisdicción rogada. 
fehaciente de que ello ocurrió, debería permitir al juez hacer un pronunciamiento de ilegalidad, e incluso, de forma inquisitiva llegar a la verdad judicial auscultando los hechos garantizando derechos de estirpe constitucional.

Si bien hoy algunas morigeraciones se han dado vía jurisprudencial, como por ejemplo el decretar pruebas de oficio en cualquier etapa del proceso (C. de E. 1990, M.P. Guillermo Chanin Lizcano; 2000, M.P. Ricardo Hoyos Duque), que a pesar de tener un sustento normativo, se requiere una mejor regulación que generalice la práctica de ese procedimiento en armonía con la Constitución.

Sobre este tópico son muchos los versados en la materia que han venido haciendo eco en inusitado inconformismo. Tratadistas como Juan Ángel Palacio Hincapié, por su parte, referencian muy oportunamente la disertación que hace Martha Sofía Tobón en el XXV Congreso de Derecho Procesal en ocasión a la jurisdicción rogada:

La noción de justicia rogada, ha surgido en la jurisprudencia colombiana como interpretación, a mi modo de ver restrictiva, de las normas que tanto el Código Contencioso Administrativo anterior como en el vigente, consagran los requisitos que debe contener toda demanda ante la jurisdicción de lo contencioso administrativa, como es la obligación de indicar las normas violadas el concepto de su violación, cuando se trata de impugnación de actos administrativos (artículo 137-4 C.C.A.) exigencia que si bien es legal, ya que fue consagrado como requisito obligatorio para impetrar las demandas ante dicha jurisdicción; debe interpretarse sin el rigor jurisprudencial de que ha sido objeto y que se ha mantenido desde 1949 hasta la fecha, como puede leerse en reiterados pronunciamientos. (Cuevas, 2015, p. 409).

En la sentencia de la Sección cuarta del Consejo de Estado (1989, exp. No. 2852):

La sala reitera la tesis de que la justicia administrativa es rogada y en ella no es aplicable el principio iura novit curia, pero precisa con relación a dicha característica una excepción: en aquellos procesos, en los cuales no se juzga la legalidad o ilegalidad de la actuación u omisión de la administración, sino que directamente se reclama la reparación del daño mediante el reconocimiento de una indemnización, el juez puede interpretar, precisar el derecho aplicable.

Corolario de lo anterior, los fallos del Consejo de Estado en los que se puede apreciar la violación de normas han sido reiterativos al 
afirmar que el principio de jurisdicción rogada nace como una manera moderadora al principio de la iura novit curia, que impone al juzgador el deber de aplicar la ley vigente, así no haya sido invocada por la parte interesada en la demanda.

Como corolario de la interpretación de esta jurisdicción rogada, la sentencia de la Corte Constitucional (1999, M. P. Antonio Barrera Carbonell), radicalizando aún más la discusión, al identificar que ni siquiera en los casos donde se violen derechos fundamentales, es posible, el desconocimiento del principio de rogatividad del derecho precisa:

Carece de toda racionalidad que presumiéndose la legalidad del acto tenga el juez administrativo que buscar oficiosamente las posibles causas de nulidad de los actos administrativos, más aún cuando dicha búsqueda no solo dispendiosa sino en extremo difícil y a veces imposible de concretar, frente al sinnúmero de disposiciones normativas que regulan la actividad de la administración. Por lo tanto, para la alta corte, no resulta irrazonable, desproporcionado ni innecesario que el legislador haya impuesto al demandante la mencionada obligación, la cual contribuye además a la racional, eficiente y eficaz administración de justicia, si se tiene en cuenta que el contorno de la decisión del juez administrativo aparece enmarcado dentro de la delimitación de la problemática jurídica a considerar en la sentencia, mediante la determinación de las normas violadas y el concepto de la violación.

De tal manera que para el Consejo de Estado aun tratándose de derechos fundamentales como el del trabajo la exigencia de la rogatividad se trata de un requisito mínimo, razonable, proporcionado y necesario, porque dicho requisito es aplicable de modo general a todas las personas que demandan actos administrativos ante dicha jurisdicción, sean o no trabajadores (C. Const. Sentencia C-197/1999, M.P. Antonio Barrera Carbonell).

En este orden de ideas, la jurisdicción rogada en lo contencioso administrativo viene limitando el espectro constitucional en detrimento de los intereses de las partes, en muchos casos de manera insoportablemente injusta7, solo por mencionar dos de los aspectos más problemáticos, en lo laboral "restructuraciones", que en ocasiones solo representan intereses políticos y clientelistas quebrantan toda suerte de derechos laborales, en las demandas contrac-

7 La versión posiblemente más conocida del argumento de la injusticia referido a normas aisladas se debe a Gustav Radbruch. Su famosa fórmula reza: "El conflicto entre la justicia y la seguridad jurídica puede ser solucionado por su sanción y el poder tiene prioridad aun cuando su contenido sea injusto y disfuncional, a menos que la contradicción entre la ley positiva y la justicia alcance una medida tan insoportable que la ley, en tanto derecho injusto, tenga que ceder ante la justicia" (Alexy, 1994, p. 34). 
tuales la flaca defensa por parte del Estado hace que los procesos terminen en favor de los grandes intereses económicos dejando al juez como testigo inmóvil en la discusión jurídica, lesionando en forma constante el interés general del Estado.

\section{DISCUSIÓN}

El desconocimiento de principios constitucionales, el excesivo procesalismo y un dogma de fe llamado principio de jurisdicción rogada, hacen que el derecho administrativo sea interpretado desde la óptica del positivismo exagerado, además de ello, la herencia kantiana y la búsqueda de la "pureza" en el derecho dada por la influencia del Círculo de Viena, una cientificidad para el derecho según el modelo de las ciencias exactas, dejan un derecho sin tiempo y sin espacio con énfasis en la validez con descuido de la legitimidad y de la eficacia, en resumidas cuentas, la identificación del derecho con la norma.

Es en la Jurisdicción Contenciosa, quizás, donde más se percibe el énfasis del excesivo procesalismo, tal y como se puede ver en el transcurrir de la historia de la jurisdicción contenciosa, la enunciación de las normas en armonía con el concepto de la violación, es el pilar fundamental para la prosperidad de las pretensiones en la demanda.

En este sentido el derecho constitucional ${ }^{8}$ (Alexy, 1994, p. 34) toma una especial importancia sobre todo con el aporte del sistema norteamericano, no $\sin$ antes advertir sobre las múltiples críticas y variopintas posiciones frente al tema ${ }^{9}$, claro está, dejando por sentada la gran diferencia entre el juez constitucional y el juez ordinario, el primero gira en torno a valores políticos decididos por el constituyente; el segundo, valores penales, civiles, laborales etc. Configurados por el legislador ordinario pasando de valores políticos después de su discusión, a valores técnicos.

La Carta Nacional (C. Constitución, 1991) le impone deberes constitucionales que le asignan al funcionario judicial la obligación de darle primacía al derecho sustancial sobre el formal, lo justo legal sobre el tecnicismo jurídico, evitando terminar en actos denegatorios de justicia, que no se compadecen con los dictados de rectitud procesal y el Estado Social de Derecho, lo cual

8 Hans Kelsen deja como punto inicial el que la Constitución es una norma jurídica, y no cualquiera, sino la primera entre todas, lex superior, aquella que sienta los valores supremos de un ordenamiento y que desde esa supremacía es capaz de exigir cuentas, de erigirse en el parámetro de validez de todas las demás normas jurídicas del sistema.

9 Ferdinand Lasalle (s.f), en Los factores reales de poder hace de la Constitución una hoja en blanco sin ninguna importancia más que política, quedando en desuso su aplicabilidad práctica en las relaciones jurídicas. 
implica un velo de injusticia en el cuestionado principio rogativo del Derecho Administrativo, punto de partida para que en la jurisdicción contenciosa se tenga crisis de la legitimidad, la cual constituye el vínculo con la voluntad popular en defensa de los derechos humanos políticos y sociales; crisis de la validez: hegemonía del criterio jerárquico; crisis de la eficacia: muchas leyes, poca justicia, poco orden y mucha impunidad (Kaufman, 1992, p. 33).

Como consecuencia de estas deficiencias, surgió así en el siglo XIX la llamada teoría general del derecho, que estigmatizó los contenidos jurídicos acercándose cada vez más a los contenidos anticientíficos y antikantianos; entendida como el modelo de ciencias exactas y del Derecho como ciencia; con marcados límites a los análisis conceptuales y estructurales.

Bajo el imperio de este formalismo también prevaleció en la metodología jurídica el concepto de que la creación del derecho sería un simple proceso lógico, concretamente la subsunción de un conjunto de circunstancias vitales bajo la norma legal. Pero que el proceso de creación jurídica muestra una estructura esencial más complicada, que contiene también momentos productivos, dialécticos, posiblemente intuitivos. En todo caso no exclusivamente lógico-formales, y que el juez nunca infiere la decisión solo de la ley, sino que llega al caso siempre con un determinado preconcepto, establecido por la tradición y la situación (Kaufman, 1992, p. 34).

De tal manera que una filosofía del derecho racional, más sencilla y maleable, no solo se ocupa de las estructuras formales, conceptuales, lógicas del derecho, sino también de sus contenidos. De la misma manera lo describe Kaufman (1992): "Mientras las obras de dogmática jurídica, que se ocupan del derecho válido, suelen envejecer en corto tiempo (pues el derecho cambia continuamente) la literatura filosófica permanece actual durante siglos, y aun milenios" (p. 34).

En el mismo sentido, el profesor Lucas Verdu (1976) sostiene que: "las reformas formales de la Constitución exigen que se supere una serie de obstáculos técnicos por causa de la rigidez constitucional, lo que impide que las realidades políticas se abran camino cuando su necesidad es urgente" (p. 34), "no se trata de hacer depender la validez de la justicia, el hombre es un ser histórico cuya esencia se encuentra en un constante cambio" (Rojas, 2001, p. 87); motivo por el cual la concepción del iusnaturalismo ha sido objeto de una notable evolución, es así, como el iusnaturalismo moderno, por ejemplo, plantea la posibilidad de un iusnaturalismo que no depende del derecho divino 
sino de las circunstancias históricas que lo rodean (Ferrater, 1979, p.1978).

Las discrepancias jurídicas son de tiempos inmemorables y de interpretaciones difusas, en cada situación en la que se presentan dudas sobre el ideal del derecho, este entra en crisis, si el encargado de administrar justicia detecta una situación alejada del derecho y puede, en un momento dado, corregir esta situación y sanearla, la dificultad se presenta en el Derecho Administrativo, con el principio de rogatividad, pues no se debe conceder lo que no se pidió en la formulación de la demanda. Una norma puede ser válida sin ser justa: en el ideal de justicia y la realidad del derecho hay siempre vacíos proporcionados o desproporcionados según los regímenes interpretativos imperantes. El ideal de justicia se devanece entre la legalidad y la justicia. Basta con poner el retrovisor en ejemplos como el de la esclavitud, no era justo, pero no por esto menos válido. Hasta hace poco existieron normas que ninguna persona racional puede considerar justas y, sin embargo, eran válidas. Un socialista difícilmente considera justo un ordenamiento que reconoce y protege la propiedad privada; así como un reaccionario difícilmente reconocerá como justa una norma que considera lícita la huelga y, sin embargo, ni el socialista ni el reaccionario dudarán del hecho de que, en un ordenamiento positivo como el italiano, tanto las normas que regulan la propiedad como las que reconocen el derecho a la huelga son válidas (Bobbio, 1992, p. 23).

En este orden de ideas, son muchas y variadas las situaciones que pueden presentar legitimización, eficacia, validez y aun una norma siendo eficaz puede llegar a ser injusta, el hecho de que una norma sea universalmente respetada no demuestra su justicia, del mismo modo que el hecho de no ser respetada no es prueba de su injusticia. La derivación de la justicia de la eficacia se podría equiparar a uno de los argumentos que de ordinario se esgrimía entre los iusnaturalistas si se puede considerar máxima de derecho natural aquella que sea aceptada por todos los pueblos (algunos decían por todos los pueblos civilizados). La respuesta a los iusnaturalistas más intransigentes a lo sumo era negativa. Y con razón: el hecho de que la esclavitud, por ejemplo, fuese practicada por todos los pueblos civilizados en cierto periodo histórico, no transformaba la esclavitud en una institución conforme a la justicia. La justicia es independiente de la validez, pero también de la eficacia. El sociólogo en sus medios puede comprender solo la eficacia del derecho; (el teórico del derecho natural) se interesa solamente por la justicia ética de las normas jurídicas y por su obligatoriedad interna (Bobbio, 1992, p. 26).

Kelsen (2011) afirmaba que todas las contrariedades jurídicas son asuntos 
que giran en torno a la validez del orden jurídico (validez del orden espacial y validez del orden personal), su mayor cualidad es haber visto con claridad la distinción entre juicio de validez y juicio de valor en el campo del Derecho y el haber negado la posibilidad de recurrir uno al otro (Bobbio, 1990). Para Kelsen (2011) "no es posible reconocer, por tanto, límites absolutos o "naturales" al poder del Estado. Los derechos de propiedad pueden ser restringidos por normas jurídicas, así, concluye que el Estado libre es aquel cuya forma es la democracia ya que la voluntad estatal es producida por los mismos que a ella están sometidos" (p. 28).

Sin embargo, definir en Kelsen (2011) cuál es esa norma fundamental, no es tarea fácil, aunque podría aproximarse a la Constitución o a la norma fundamental de un ordenamiento jurídico, pero al no poder encontrarle, a su vez, un fundamento último meramente formal de su validez aparece como una importante carencia en su intento de crear una teoría del Derecho completamente formal.

Como honrosa excepción cabe mencionar al positivista Radbruch (1999), que se dio cuenta de los evidentes peligros que estas posiciones teóricas pueden acarrear; señaló que, si no se puede saber lo que es justo, ante dicho vacío alguien tendría inevitablemente que indicar qué es lo legal. Este último jurista llegó incluso a reconocer sin ambages que pueden existir leyes de contenido arbitrario e, incluso, delictivo. "Cuando uno se acerca al pensamiento iuspositivista es importante tener claro que legalidad no es lo mismo que justicia; esto es un antídoto fundamental” (p. 35).

No sé si acertadamente, Popper (1945) denunció, años más tarde, en su Sociedad Abierta, que la teoría pura del Derecho de Kelsen (2011) "es una pseudo-ciencia como el marxismo o el freudismo, que son consideradas irrefutables por ser todos sus enunciados verdaderos por definición, pero que no nos dicen nada de la realidad" (p. 419), es reprochable para algunos académicos que el objeto de la interpretación jurídica esté configurado únicamente por las normas, dejando por fuera los hechos, disquisición esta que podría ser compartida entendiendo situaciones distintas frente a la consecución de un mismo fin.

La jurisdicción contenciosa administrativa es quizá donde el fenómeno se aprecia con mayor dinamismo, si se tiene en cuenta el interés general del que debe y tiene que estar desprovisto la administración, así, un juez constitucional se enfrenta a situaciones totalmente diferentes a la de un juez ordinario, 
para este último se trata de un conflicto entre fidelidad a la ley y la justicia del caso concreto, esto es, de la justicia individual frente a la ley, en tanto que para el juez constitucional la situación es frecuentemente la contraria: una situación en que la norma satisface la justicia individual, pero que amenaza en su estricta consecuencia lesionar los valores generales. Dicho de otra manera, el conflicto no está en el contraste entre fidelidad a la norma y justicia individual, sino en el enfrentamiento entre el mandato jurídico y la racionalidad o la necesidad política, entre el rigor de la norma y la exigencia del bien general (García, 2007a).

Lo que la experiencia de la justicia constitucional ha revelado es justamente la aparición de un reino nuevo donde extender el imperio del derecho, un reino hasta entonces dejado al capricho y al arbitrio de los políticos, el reino de la Constitución, concebida no como una simple decisión existencial, consumada en un momento único y remitida en su suerte a todos los avatares y las pasiones de la lucha política ulterior, sino como una norma jurídica efectiva, que articula de manera estable los elementos básicos del orden político y social y que es capaz de funcionar normativamente como clave de bóveda del sistema jurídico entero.

Dworkin de manera un tanto quijotesca si se quiere, parte de un cognitivismo constitucional, según el cual todo juez es capaz de interpretar de forma acertada la Constitución en todos los casos. Desde su visión, las disposiciones constitucionales, y sobre todo aquellas que anuncian los derechos fundamentales, contienen para cada controversia jurídica una única solución correcta, una verdad sustancial palpable. El intérprete debe empeñarse en descubrir esta única verdad, mediante una lectura moral de los principios abstractos de la Constitución (Dworkin, 1994, p. 475).

Sin entrar en debates marxistas de estructuras y superestructuras, sí tenemos que decir que el panorama de los estados es el mismo en todos los países de Latinoamérica, la organización del Estado de derecho no ha podido satisfacer en índices aceptables las demandas de seguridad ciudadana, de protección de la vida y las libertades y la provisión del mínimo vital, se señala, está justificado el activismo de la Corte Constitucional. La ineficacia del Congreso y del Ejecutivo genera un vacío de poder, que deslegitima el Estado y pone en riesgo los derechos fundamentales que la Constitución garantiza. Comoquiera que la función de la Corte consiste en velar por la integridad de los derechos fundamentales, su papel debe robustecerse en la escena política y suplir el déficit de los poderes del Estado, cuya negligencia conduce a un estado de 
cosas contrario a lo prescrito por la Constitución (Bernal, 2007).

\section{COMENTARIO FINAL}

Por otra parte, considera el insigne jurista García de Enterría (2007), en cita que hiciera de Schmitt, el Tribunal Constitucional no llega a conocer ni de verdaderos conflictos constitucionales ni tampoco de un litigio verdadero, en el sentido procesal y técnico del concepto. No hay conflicto constitucional, porque para que lo hubiese en sentido correcto las partes en conflicto deben estar en una cierta relación a la Constitución de la que resulte su papel de partes en función de su legitimación activa y pasiva.

Es el Tribunal Constitucional un legislador, solo que no es un legislador positivo, sino un legislador negativo, dice Kelsen (2011). El poder legislativo se ha escindido en dos: el legislador positivo, que toma la iniciativa de dictar y de innovar las leyes, y el legislador negativo, que elimina aquellas leyes que nos son compatibles con la superior norma constitucional (García, 2007b).

Se debe cambiar por una concepción del ordenamiento jurídico de textura abierta y no cerrada como el heredado de Kelsen (2011), puesto que es necesario buscar esas soluciones más allá de la ley y con un mejor enfoque constitucional. Las posiciones estudiadas dimanan en un principio de la rogatividad que a nuestro entender -y es el tema que proponemos estudiar- limita el desarrollo del derecho, pues con ello se desconocen situaciones fácticas del derecho importantes para el objeto en estudio, más si se tiene en cuenta el viraje del Derecho Administrativo, parafraseando a Luigi Ferrajoli (2004): "el estado nacional ha perdido el monopolio exclusivo de la producción jurídica, esto apoyado en la idea en que el derecho estatal se encuentra cada vez más relevado, suplido y suplantado por formas de regulaciones" (Penagos, 1996, p. 34).

Los derechos sociales son bautizados por algunos como "derechos humanos de segunda generación" (Blancas, 1994, p. 27), dada su aparición en un segundo momento histórico, y no está referido a la tutela de la esfera de libertad del individuo sino al logro de la igualdad real o material y de la justicia social. En el mismo sentido y de manera más profusa, la Sentencia C-197 de 1999 de la Corte Constitucional (M.P. Antonio Barrera Carbonell) estipula la especial importancia de reincorporar al ordenamiento jurídico los derechos fundamentales, de tal manera que en los procesos administrativos en donde se trastoque el derecho al trabajo de los coasociados es necesario su protección inmediata, aunque la jurisdicción de lo contencioso administrativo 
tiene unas funciones constitucionales diferentes a la jurisdicción ordinaria y a la constitucional, dado que hace parte de la rama judicial y administra justicia le son aplicables las disposiciones generales establecidas en los artículos 2, 3, 4, 6, 209, 228, 229 y 230 de la Constitución.

No obstante lo anterior, debe advertir la Corte que, en virtud del principio de la prevalencia del derecho sustancial, no se debe extremar la aplicación de la norma acusada, al punto tal que se aplique un rigorismo procesal que atente contra dicho principio. En tal virtud, defectos como la cita errónea de una disposición legal que por su contenido es fácilmente identificable por el juez, o el concepto de la violación insuficiente pero comprensible, no pueden conducir a desestimar un cargo de nulidad. Considera la Corte, que, tratándose de derechos fundamentales de aplicación inmediata, el juez administrativo a efecto de asegurar su vigencia y goce efectivos debe aplicar la correspondiente norma constitucional, en forma oficiosa, así la demanda no la haya invocado expresamente.

Las discusiones sobre la naturaleza jurisdiccional de los tribunales constitucionales no son ni serán un tema pacífico, en los tiempos de Weimar Hans Kelsen ya se había discrepado sobre la legitimidad de la justicia constitucional. La contundente arremetida de Schmitt puso en entredicho el carácter jurisdiccional del Tribunal Constitucional, y acusó a la institución ideada por Kelsen (2011) de socavar el dogma de la división de los poderes públicos, y de hacer de la política un asunto de la justicia. Así mismo, el autor alemán presagió que la jurisdicción constitucional llevaría inexorablemente al gobierno de los jueces, y -en conocidas palabras de Guizot- a la judicialización de la política y la politización de la justicia, con la cual la justicia tiene todo que perder y la política nada que ganar (Bernal, 2007).

Sin embargo, es necesario entender la Constitución no como mecanismo de interpretación, sino, como mecanismo de garantía para afianzar los principios y valores constitucionales (Pizza, 1993, p. 123). La importancia de la Constitución está en que la idea de la legalidad se vea reforzada y en parte coadyuvada, por la idea de la constitucionalidad; la tradicional concepción de la Constitución como norma meramente organizativa y metajurídica, se ve sustituida por una concepción de la Constitución entendida como norma directamente eficaz.

No es la figura del operador jurídico la máquina que se encarga de acomodar una situación al sistema normativo, sin una sujeción estricta a la ley, más que 
eso es necesario mirarlo como el medio controlador de la legitimidad constitucional, un funcionario crítico del derecho.

Se puede expresar el cambio de paradigma del derecho producido por la constitucionalización rígida de estos principios, afirmando que la legalidad, merced de esto, resulta caracterizada por una doble artificialidad: la del ser del derecho, es decir su existencia, -ya no derivable de la moral ni de la naturaleza, sino, precisamente, puesta por el legislador- como también la de su deber ser, es decir, de sus condiciones de validez, así mismo positivadas con rango constitucional, como derecho sobre el derecho, en forma de límites y vínculos jurídicos a la producción jurídica. No se trata de eliminar o de poner en crisis la separación entre derecho y moral realizada con el primer positivismo, sino, por el contrario de completar el paradigma positivista, idea fundamental de Kelsen (2011), y al mismo tiempo el Estado (Ferrajoli, 1999), lo cual implica garantías desde la producción de la norma ya que el legislativo queda inmiscuido en las garantías constitucionales del Estado Social de Derecho.

En resumen, dos claros conceptos de Constitución: el primero, el carácter normativo jurídico, y el segundo, de contenido preponderantemente ideológico; la primera norteamericana, la segunda francesa y continental, situación esta que hace una mejor búsqueda del fenómeno constitucional (Santofinio, 2015, p. 367). Lo cual hace necesario inmiscuir a la administración de justicia en el cumplimiento de las normas constitucionales como garantía para el ciudadano en la consecución del derecho (Parejo, 1998, p. 109). Desde una u otra óptica, tesis totalmente contraria a autores como Otto Mayer (1924), quien de manera tajante dice: "en el sentido de que el derecho constitucional pasa mientras el derecho administrativo permanece" (p. 367).

Necesario es anotar, que lo anterior, ni es una creación propia de nuestro derecho constitucional y menos una elaboración doctrinaria de los novísimos apóstoles del nuevo derecho. No, ello hace parte de la más rancia tradición jurídica occidental que desde Aristóteles hasta el derecho romano, desde este a Santo Tomás y desde aquel hasta el realismo jurídico han definido el derecho como "LA COSA JUSTA" (C. de Estado, 10 feb/2011, M.P. Gustavo Eduardo Gómez Aranguren).

En resumidas cuentas, un Estado constitucional de derecho, el cual se encuentra en yuxtaposición al "Estado legal de derecho". Conforme a este paradigma, la Constitución ya no es solo la declaración de unas libertades básicas sino, antes bien, una norma directamente operativa que contiene 
el reconocimiento de garantías exigibles jurisdiccionalmente, las cuales, en muchos casos, esas garantías tienen una estructura normativa abierta e indeterminada que impone a quien debe aplicarlas una tarea que excede la de interpretar una norma.

Desde nuestra óptica, el juez debe ser el vigilante del proceso, esto es, de cada una de las partes; si las condiciones de aplicabilidad de la norma están indeterminadas, lo cual implica un sinnúmero de opciones, el juez, debe incluir esos argumentos en su decisión, asumiéndolos como propios o refutándolos adecuadamente, que su adecuación de manera razonable, y lo más importante la participación procesal de los litigantes en el debate normativo. En ese orden de ideas, la jurisdicción rogada pasa de ser un principio de marcadas connotaciones petrificadas en el proceso, a un aspecto vetusto en las connotaciones estructurales del nuevo Estado.

Las teorías dialécticas y consensuales, que ayudan a conservar la imparcialidad judicial, pueden ser mejor aplicadas a los procedimientos con alto componente de creación legal. De una u otra forma el juez tiene una función en el nuevo marco jurídico del Estado colombiano, y es, dejar de ser un simple revisor de normas, ni mucho menos un testigo inmóvil del desenvolvimiento de las controversias entre los particulares o entre estos y el Estado, su función es más activa, dotado de facultades inquisitivas que le da el Derecho Administrativo la posibilidad de esclarecer la verdad.

En este sentido, el principio iura novit curia en los procesos contenciosos administrativos, tesis contraria al paradigma de la jurisdicción rogada en los procesos contenciosos, permite un verdadero avance metajurídico en la evolución del derecho, más aún, este debe ampliarse, permitiendo que todas las partes procesales intervengan el proceso, reglas de este tipo son las que propone Juris Oliveira (2003), quien propicia un nuevo alcance de la regla iura novit curia.

Las partes pueden y deben aportar su cooperación también en cuanto a la valorización jurídica de la realidad externa al proceso, investigación que de ningún modo puede ser hoy labor exclusiva del órgano judicial. La expectativa de éxito final en la causa evidenciada, en verdad, el interés primordial de la parte en dar a conocimiento del tribunal la norma jurídica a ser aplicada, según su visión particular. Es fundamental reconocer que los constantes cambios legislativos de las normas la hacen de una complejidad tal que puede darse el serio riesgo de que las partes o jueces no "descubran" la 
norma adecuada o no la interpreten correctamente. En este orden de ideas, es importante establecer el contenido o alcance de la norma para disminuir las consecuencias negativas en el derecho de defensa. Además de eso, es inadmisible que las partes sean sorprendidas por una decisión que se apoye fundamentalmente en una visión jurídica de la que no estén en conocimiento. El tribunal debe, por lo tanto, dar conocimiento previo de qué dirección o derecho subjetivo corre peligro, lógicamente sin adentrarse en el espeso pantano del prejuzgamiento (De Olivera, 2003, p. 227).

Las concepciones filosóficas propias de la hermenéutica del derecho no pueden limitarse exclusivamente a lo formal y descuidar los contenidos, o sea, dejárselos a la política, de tal manera que urge la necesidad de reestructurar nuestros paradigmas críticos e incrustar o entrelazar fórmulas que permitan reevaluar sus tesis, de tal manera que podamos revincular la legitimidad, validez y la eficacia en la interpretación del derecho con la firme intención de avanzar en el modelo de justicia que permita un mejor engranaje social.

No tiene ningún sentido juzgar a las corrientes anteriores (iusnaturalismo, iusformalismo, iusrealismo), tampoco tomar partido por alguna de ellas, porque podemos observar que cada una tiene su particular concepción y conceptualización del derecho. Lo verdaderamente trascendental es percibir no solo la existencia de varias corrientes sino también las diversas metodologías utilizadas. Cada una de estas escuelas analiza al derecho desde una óptica que apunta a una perspectiva diferente del mismo fenómeno. Al iusnaturalismo le interesan los "valores"; al iusformalismo, las "normas", y al iusrealismo, los "hechos". En este sentido, resulta inobjetable que cada una de estas perspectivas tiene sus aciertos y sus errores al considerar distintos aspectos del mismo fenómeno.

De las tres posturas, podemos tomar lo que nos sea de utilidad. Sin embargo, parece imposible dar un concepto unívoco del derecho, por la sencilla razón, de que se trata de definirlo desde tres diversos puntos de vista: El aspecto axiológico, el normativo y el fáctico. Con gran acierto, Eduardo García Máynez (2010) apunta: "El error de quienes han pretendido encerrar en una sola definición (en el caso del derecho) objetos diferentes entre sí, no implica únicamente confusión de puntos de vista, sino, lo que es peor, concomitante confusión de los objetos contemplados" (p. 17). 


\section{CONCLUSIÓN}

Un análisis lógico de estos aspectos viene a demostrar que lo anterior puede formar parte de una misma concepción del derecho. El aspecto axiológico, al derecho como valor; el normativo, al derecho como norma; y, el fáctico, al derecho como realidad. La inocencia académica que a muchos nos caracteriza en temas de este tipo nos empuja a preguntarnos: ¿por qué no concatenar los tres aspectos que son de suma importancia para el estudio del derecho en el ideal de justicia? Al hacernos esta pregunta descubrimos teorías verdaderamente interesantes en algunos pensadores. Tal es el caso de la teoría tridimensional del derecho y de la teoría integral del derecho, cuyos exponentes son Miguel Reale (1989) y Luis Recaséns Siches (1985), respectivamente. En ambas teorías, la concepción del derecho conserva las tres dimensiones de las que se ha tratado -valor, norma y hecho- pero estrechamente unidas entre sí en relaciones de esencial implicación. El derecho no es un valor puro, ni una mera norma con ciertas características especiales, ni es un simple hecho. Recaséns Siches (1985) señala que "en la realidad del derecho se dan, recíproca e indisolublemente trabadas entre sí tres dimensiones: hecho, norma y valor. El derecho es un hecho, una obra humana, estimulada por la conciencia de unas necesidades en la vida social; obra producida bajo forma normativa; y que en su función para satisfacer esas necesidades, intenta hacerlo de acuerdo con la realización de unos valores específicos" (p. 40).

De hecho, la teoría tridimensional postula que donde exista un fenómeno jurídico, hay irremediablemente un hecho subyacente -hecho económico, político, o social-, un valor que confiere determinada significación a ese hecho, que inclina o determina la acción de los hombres para alcanzar o preservar cierta finalidad u objetivo; y finalmente, una norma que representa la relación o medida que integra a uno de aquellos elementos con el otro: al hecho y al valor. Además, se afirma que tales elementos -hecho, valor $y$ norma- no existen separados uno de otro, sino que coexisten perfectamente, pues no se excluyen, ni se implican. Es decir, son absolutamente inseparables $y$, por tanto, no hay ninguno que sea más importante que los otros. Ahora bien, esos factores no solo se exigen recíprocamente, sino que actúan como uno solo. De tal modo, la vida del derecho resulta de la interacción dinámica y dialéctica de los tres elementos que la integran (Reale, 1989, p. 69).

Cabe evocar las enseñanzas del filósofo de Königsberg, quien destacó dos formas puras de intuición sensible: espacio y tiempo. El estudio de la historia demuestra que el derecho no ha sido el mismo en todas las coordenadas espacial-temporales. Al respecto, Norberto Bobbio (1991) comenta que, para 
formular leyes y principios universales en materia de la ciencia del derecho, es preciso atender no solo a la naturaleza humana, sino a las "condiciones históricas que determinan las cambiantes leyes de pueblo a pueblo, de tiempo a tiempo" (pp. 35-51).

No tiene justificación alguna que el error del ciudadano, el cual por lo demás no es un experto en regulaciones jurídicas ni avezado en las lides de doctrina constitucional, sirva para que el juez eluda la obligación de controlar la arbitrariedad de la actuación de la administración y declare ajustado a las normas un acto que corrompió el ordenamiento jurídico. La existencia del Estado Social de Derecho implica obligaciones sociales para el juez y la armonización del ordenamiento jurídico en las relaciones de convivencia que aseguran el orden justo en lo político, lo económico, lo social, lo cultural y con respeto al derecho de igualdad. De allí se deriva que la actividad judicial no debe exigirse, con la exégesis en que normalmente se hace, escudándose en la inexistencia del concepto de la violación o la indicación de la norma precisa, pues existe una norma superior que le da toda la facultad de actuar contenida en la misma norma política.

\section{REFERENCIAS BIBLIOGRÁFICAS}

Bernal, C. (2007). El derecho de los derechos. Bogotá: Universidad Externado de Colombia.

Blancas, C. (1994). Estado social, Constitución y derechos fundamentales. En. Constitución, trabajo y seguridad social. Lima: ADEC-ACTA.

Bobbio, N. (1990). Contribución a la Teoría del Derecho. Madrid: Editorial Debate.

Bobbio, N. (1990). Teoría general del derecho. Madrid: Debate.

Colombia. Consejo de Estado. Sala de lo Contencioso Administrativo. 10 de febrero de 2011. Sección segunda "a". Consejero Ponente: Gustavo Eduardo Gómez Aranguren. Rad. 0448-10.

Colombia. Consejo de Estado. Sala plena. Sentencia de 1 de febrero de 2000. Consejero Ponente: Ricardo Hoyos Duque. Rad. AC-7974.

Colombia. Consejo de Estado. Sección cuarta. Auto de 3 de agosto de 1990. Consejero Ponente: Guillermo Chanin Lizcano. Rad. 2.739.

Colombia. Corte Constitucional. Sentencia C-197 de 7 abril de 1999. M.P. Dr. Antonio Barrera Carbonell.

Colombia. Sentencia de 30 de julio de 1993. Redicado 2262. M. P. Yesid Rojas Serrano.

Colombia. Sentencia 8 de junio de 2000. Radicado 11121. M. P. María Elena Giraldo Gómez.

Colombia. Sentencia de 17 de agosto de 2000. Radicado 12640. M. P. Alier Hernández. 
Cuevas Cuevas, E. (2015). Memorias XXV Congreso de derecho procesal. Cartagena: Universidad Libre.

De Oliveira, A. (2003). Garantía do Contradictorio (2a ed.). Sao Paulo: Saraiva.

Dworkin, R. (1994). ¿Realmente no hay una respuesta correcta en los casos difíciles? Lecturas del pensamiento jurídico contemporáneo. Barcelona:

Ferrajoli, L. (1999). Derechos y garantías. Madrid: Editorial Trotta.

Ferrater, J. (1979). Diccionario filosófico. Barcelona: Editorial Ariel S.A.

García de Enterría, E. (1991). Constitución como norma y el tribunal constitucional. Madrid: Editorial Civitas, S.A.

García de Enterría, E. (2007a). La lucha contra las inmunidades del poder en el Derecho Administrativo. Bogotá: Editorial Civitas S.A.

García De Enterría, E. (2007b). Las transformaciones de la justicia administrativa: de excepción singular a la plenitud jurisdiccional. Madrid: Editorial Civitas S.A.

Karl, P. (2010). La sociedad abierta a sus enemigos. Barcelona: Editorial Paidós.

Kaufman, A. (1992). La filosofía del derecho en la posmodernidad. Bogotá: Editorial Temis.

Kelsen, H. (2011). Teoría pura del derecho. Madrid: Trotta.

Luciano, A. Manual de derecho administrativo. Bogotá Editorial Ariel S.A.

Pizza, R. (1993). La jurisdicción constitucional costarricense. En Justicia Constitucional comparada (p. 123). México: UNAM.

Radbruch, G. (1999). Relativismo y derecho. Bogotá: Editorial Temis.

Reale, M. (1989). Introducción al derecho. Madrid: Pirámide.

Recaséns, L. (1985). Introducción al estudio del derecho y tratado general de filosofía del derecho. México: Porrúa.

Rojas, G. (2001). Filosofía del derecho. Bogotá: Ediciones Librería del Profesional.

Santofinio, J. (2015). Derecho administrativo. Bogotá: Universidad Externado de Colombia. 